\title{
Psychosocial Wellbeing Among Rural Migrant Workers in China: Did the 2008 Financial Crisis Worsen Their Vulnerability?
}

\author{
Jason Hung ${ }^{1}$ \\ ${ }^{1}$ Institute of Education, University College London, London, the United Kingdom \\ Correspondence: Hung, Jason, Institute of Education, University College London, London, the United Kingdom. \\ E-mail: sociowriting@jasehung.com
}

Received: November 10, 2019

Accepted: November 30, 2019

Online Published: December 31, 2019

doi:10.5539/ass.v16n1p54

URL: https://doi.org/10.5539/ass.v16n1p54

\begin{abstract}
Background. Since 1980, China has been experiencing the largest migration in human history to urban areas. Rural migrant workers are exposed to disproportionate stress, a sense of marginality, language barriers and low social positions. Stress plays a significant role in the development of psychosocial challenges, including anxiety, hostility and depressive symptoms, as well as diagnosable conditions, including compulsive and post-traumatic stress disorders. This project questions whether rural migrant workers were particularly vulnerable in terms of psychosocial wellbeing after the collapse of Lehman Brothers, one of the major incidents marking the worst turmoil of the 2008 financial crisis.

Methods. Data from the Rural Urban Migration in China (RUMiC) 2007-08 and 2008-09 datasets were used for analyses. General Health Questionnaire (GHQ) -12 scores, categorised as the presence of common mental disorders (CMDs) vs. the absence of CMDs, were chosen as the dependent variable. Socioeconomic status was measured as per hukou status, job nature and working hours, each treated as an independent variable. City, gender, age, ethnicity and educational level were taken into account as confounders. Cross-tabulations and binary logistic regression analyses were run. The software package STATA 14.2 was used for secondary data analysis.

Results. The more educational qualifications rural migrant worker samples received, the more likely they were to be free from CMDs. However, tertiarily-educated rural migrant worker samples enjoyed similar levels of mental wellbeing as their counterparts who had completed elementary school or below. Additionally, there was no statistical evidence to suggest that rural migrant worker samples were more likely to experience CMDs based on their job nature (non-manual vs. manual vs. self-employed vs. family business) or working hours ( $<60$ hours per week vs. 60-119 hours per week vs. $>=120$ hours per week).

Conclusions. The optimal rural migrant workers' educational level, in terms of maximising their mental wellbeing, was between senior secondary school and post-secondary school level. However, socioeconomic factors, namely, job nature and working hours, were insignificant determinants of mental wellbeing of rural migrant workers. Moreover, there was no evidence suggesting rural migrant workers suffered from a distinct mental wellbeing between 2008 and 2009.
\end{abstract}

Keywords: psychosocial wellbeing, educational attainment, occupation security, internal migration, financial crisis

\section{Introduction}

Since 1980, China has been experiencing the largest migration in human history, as hundreds of millions of rural dwellers relocate, temporarily or permanently, to urban areas (Gong et al., 2012, p. 843; Editorial, 2014, p. 1902). According to the China Population Census, the rural migrant worker, also known as rural-urban migrant worker or locally referred to as nonmingong (农民工), population increased from 30 million in 1980, to 132 million in 2006 and 262 million in 2010 (National Bureau of Statistics, 2007; Fong \& Tong 2015, p. 1087).

In China, each citizen is assigned as either a rural or urban hukou status (户籍), based on their maternal hukou status (Fu \& Ren, 2010, p. 593; Song \& Sun, 2016; Tani, 2017, p. 48). The hukou system, also known as the household registration system, was initiated in 1958 to control the movement of the Chinese population (Gallagher et al., 2009, p. 30; Fan, 2008, p. 66). Those in possession of a rural hukou can only gain access to 
state benefits and opportunities designated for rural Chinese communities (Young, 2013, p. 28; Davin, 1999, p. 7; Gaetano, 2015, p. 30; Chan \& Zhang, 1999, p. 819). When individuals migrate to urban spaces, they remain ineligible for any social welfare - including healthcare, unemployment insurance, pensions, subsidised education and housing - allocated to urban Chinese communities (Fan, 2008, p. 68; Wang, 2005; Chan \& Zhang, 1999, p. 819; Tani, 2017, p. 48). Primarily due to their rural hukou status, rural migrant workers endure long working hours and insecure employment, while tolerating overcrowded and insalubrious living conditions (Lau et al., 2012, p. 526; Li et al., 2007, p. 718).

High unemployment in agricultural provinces has meant that many local rural dwellers are increasingly migrating to cities (Chan, forthcoming; Chan, 2015, p. 36). In Dongguan, for example, due to the significant reduction in aggregate supply of labour to both the agricultural and industrial sector, rural workers usually possessed short work tenure, in part, leading to the rise in rural unemployment or underemployment (Chan, 2010a, p. 517). This research project exclusively focuses on rural migrant workers, a population that continue to face significant socioeconomic difficulties.

Rural migrant workers are exposed to disproportionate stress, a sense of marginality, language barriers and low social positions (Song \& Sun, 2016; Cheung, 2013, p. 122; Bankston \& Zhou, 1997; Kulis et al., 2009; Noh \& Avison, 1996; Young, 2001). Stress plays a significant role in the development of psychosocial challenges, including anxiety, hostility and depressive symptoms, as well as diagnosable conditions, including compulsive and post-traumatic stress disorders (Yu et al., 2017, p. 468; Lin et al., 2011, p. 172; Cheung, 2013, p. 122; Cheung, 2014). Here psychosocial wellbeing pertains to the influence of social factors on an individual's mind or behaviour (Martikainen et al., 2002, p. 1091).

Following the Lehman bankruptcy, from the fourth quarter of 2008, firms which established pre-crisis relationships with less financially healthy lenders had a slimmer chance of obtaining loans, or paid higher interest rates if they needed to borrow. These financial constraints, in part, resulted in mass redundancies as firms decided to reduce employment to cut operational expenses (Reich, 2014, p. 1). The credit crisis morphed into recessions across developed economies around the globe (Wim, 2009, p. 1; Bourkhis \& Nabi, 2013, p. 68). Simultaneously, world trade collapse in agricultural products - particularly natural resources - occurred between the second quarter of 2008 and the third quarter of 2009, marking the steepest fall of world trade in recorded history (Gawande et al., 2011, p. 5; Braun, 2008, pp. 2, 8). In 2008, financial turmoil worldwide resulted in an estimated total loss of US\$50 trillion. Existing studies argued the economic meltdown was exacerbated due to the aftermath of Lehman Brothers' bankruptcy in September 2008 (Aisen \& Franken, 2010, p. 3; Jones, 2010, p. 2).

By the end of the third quarter of 2008, Guangdong, the most popular province for rural migrant workers seeking occupational development, recorded that a total of 7,148 enterprises had been liquidated or moved to areas with lower production costs (Chan, 2010b, p. 665). By the end of the fourth quarter of 2008, as many as 8,500 enterprises and over 50,000 factories had been shut down (Chan et al., 2010, p. 59; Chan, 2010a, p. 665). From a nationwide perspective, multimillion China-based factories were closed as a direct result of the 2008 financial crisis (Zhang, 2015, p. 66).

The liquidation of many labour-intensive enterprises and factories created increased unemployment rates among rural migrant workers (Liu 2011 p. 73). At the end of 2008, the Ministry of Agriculture estimated approximately 20 million of a total of 130 million rural migrant workers had lost their jobs (Zhang, 2015, p. 69; Chen et al., 2012). Of those employed in September 2008, only $2.90 \%$ ( 8.7 million out of 279 million) were unemployed in April 2009 (Zhi et al., 2013, p. 259). Here statistics indicate that most rural migrant workers remained employed or those being laid-off were reemployed by April 2009, despite the mass liquidation of firms and factories caused by the financial crisis. However, as Huayong Zhi et al. (2013, p. 259) argued, less than half of laid-off rural migrant workers in late 2008 were rehired in non-agricultural jobs by April 2009 (Jia, 2014, p. 39). The majority of rural migrant workers were therefore denied the opportunities to engage in urban jobs, opportunities that they were predominantly motivated by to migrate from rural to urban spaces.

\subsection{Educational Attainment and Psychosocial Wellbeing}

Bao Liang Zhong et al. (2015, p. 2), and Yang Cao and Zhenhui Liu (2015, p. 464), measured the levels of psychosocial wellbeing of poorly educated rural migrant workers. They found that rural migrant workers with an education of junior high school level or below suffered from lower earnings, worse working conditions and greater social strain, when compared to their better educated counterparts (Zhong et al., 2015, p. 5; Cao \& Liu, 2015, p. 465). Findings corresponded with results obtained from alternative studies (e.g. Zhu et al., 2012, pp. 497, 501; Frenkel \& Chongxin, 2015, pp. 262, 266, 268). 


\subsection{Socioeconomic Difficulties and Psychosocial Wellbeing}

According to Article 5 of The Temporary Regulation on the Administration of Cross-Provincial Employment of Migrant Workers, issued by the Ministry of Labour in 1994, urban job opportunities for rural migrant workers should be considerably restricted, a policy in favour of employment security for local urban dwellers ( $\mathrm{Li}, 2006, \mathrm{p}$. 59). As a consequence, since 1997, the reform of state-owned enterprises (SOEs) in cities has significantly discriminated against rural migrant workers in the urban labour market, as SOEs favour the recruitment of unemployed local urban dwellers. By the end of the 1990s, local governments had forced SOEs to dismiss rural migrant workers, creating more job vacancies for local urban residents (Sylvie et al., 2011, p. 2). Not only did rural migrant cohorts fail to gain job security, they were denied the right to employee benefits. In profit-sharing firms, for example, local urban workers were exclusively eligible for a share of company profits (Maurer-Fazio \& Dinh, 2004, p. 174). With the least occupational security, welfare and status, rural migrant workers were generally permitted to work in positions that local urban dwellers were unwilling, or less willing, to undertake (Knight et al., 1999, p. 74).

Migrant cohorts are often required to accept jobs with long working hours, limiting the time they are available to maintain social bonds with family, or build metropolitan networks (Li et al., 2007, pp. 717-718). These forms of discrimination discourage them from aggregating their social resources and exhibiting social confidence (Li et al., 2007, pp. 717-8; Shen et al., 1998, p. 5370). Further evidence demonstrating their failure to secure social resources includes, for example, their experiences of residential segregation from local urban residents due to their denigration as "second-class citizens", and uncommon dialects and customs (Zhan, 2011, p. 265). Existing Chinese studies argue social subordination in association with rural migrant status is related to higher levels of perceived discrimination (Hu \& Chen, 2012; Jin et al., 2012; Lin et al., 2011; Yang et al., 2012).

These discriminatory circumstances aggravate rural migrant workers' levels of distress (Liu et al., 2008). A total of 48 existing studies demonstrate that rural migrants facing greater exclusion displayed symptoms of social strain. Symptoms included interpersonal sensitivity, social anxiety and hostility (e.g. Zhong et al., 2013, p. 1571; Liu et al., 2009; Li et al., 2008; Liu et al., 2008). Here social exclusion, in part, referred to the separation of networks between local urban residents and rural migrant workers. The latter experienced substantial difficulties when establishing connections with the former (Zhan, 2011, p. 265).

\section{Research Aims and Hypotheses}

Aforementioned literature (Li, 2006; Sylvie et al., 2011; Maurer-Fazio \& Dinh, 2004; Knight et al., 1999; Li et al., 2007; Shen et al., 1998; Hu \& Chen, 2012; Jin et al., 2012; Yang et al., 2012; Zhong et al., 2013; Liu et al., 2009; Liu et al., 2008; Zhan, 2011) rarely explores the intersection between socioeconomic and psychosocial challenges faced by rural migrant workers during the 2008 financial crisis. Furthermore, most of these studies restrictively address migrant cohorts' encounters in the regions of Pearl River Delta (珠江三角洲) and the Yangtze River Delta (长江三角洲). These regions are limited to provinces/cities - including Guangdong, Shanghai, Jiangsu, Zhejiang and Anhui - where the majority of rural migrant workers are situated (e.g. Fong \& Tong, 2015; Zhang, 2015).

This project expanded the sociological inquiry into broader geographical contexts and studied rural migrant workers' experiences within and beyond both delta regions. A total of 15 provinces/cities with the greatest concentration of rural migrant workers, including Guangzhou, Shenzhen, Nanjing and Shanghai were examined (Table 1). The research aim was to gain a better understanding of the causal association between socioeconomic and psychosocial challenges encountered by rural migrant workers during the 2008 financial crisis. The project questions whether rural migrant workers were particularly vulnerable in terms of psychosocial wellbeing after the collapse of Lehman Brothers, one of the major incidents marking the worst turmoil of the 2008 financial crisis. Vulnerability in sociological discussion refers to the experiences of conditions that would harm ones' social values. These conditions include poverty and inequality, marginalisation, access to insurance and housing quality (Brooks, 2003, p. 4).

In the late 2000 s, rural migrant workers contributed approximately $16 \%-24 \%$ of GDP, in addition to around $33 \%$ - 40\% of net income in rural China (Wang, 2010, p. 218). Circumstances which inflict psychosocial challenges on rural migrant workers reduce their workplace efficiency and capacity for work, potentially compromising national economic growth (Wang et al., 2017, p. 1386; Liu et al., 2011, p. 210). Furthermore, discrimination and alternative forms of social exclusion are human rights abuses, prompting the need for early identification and intervention (World Health Organisation, 2013).

This project set up two hypotheses, as follows: 
Hypothesis 1:

Socioeconomic challenges faced by rural migrant workers were negatively associated with their psychosocial wellbeing in China, between 2008 and 2009.

Hypothesis 2:

Socioeconomically insecure rural migrant workers were more vulnerable in terms of psychosocial wellbeing, relative to their socioeconomically secure counterparts, in 2009 than in 2008.

\section{Ethics}

This study received approvals from Rural Urban Migration in China (RUMiC) team to conduct secondary data analysis in accordance with an end user license agreement obtained from Institute of Labour Economics (IZA).

\section{Research Design and Data}

\subsection{RUMiC Data}

Data from the RUMiC 2007-08 and 2008-09 datasets were used for analysis. RUMiC is a large-scale, five-year longitudinal and representative survey of Chinese rural migrants from 2008 to 2012 (Zhao, 2015, pp. 88-9; Lee \& Zhao. 2015; Zhang, 2017, p. 115; Akgüc et al., 2014). The survey was the joint venture of researchers at the Australian National University, the University of Queensland and the Beijing Normal University, with support from the IZA (Fang et al., 2015; Fang, 2017, p. 15). The RUMiC consists three of independent surveys: the Rural Household Survey (RHS), the Urban Household Survey (UHS), and the Migrant Household Survey (MHS). Both wave 1 (in 2008) and wave 2 (in 2009) of the MHS include detailed information about personal characteristics, educational attainment, socioeconomic status and mental health status, as shown in Table 2 (Tani, 2015; Lee \& Zhao, 2015).

A pre-census was undertaken by the RUMiC survey team to form a sampling frame based on workplaces of migrant workers (Garnaut et al., 2008 pp. 177-178; Akguc et al., 2014). Under this frame, 5,000 migrant households were selected by simple random sampling, based on samples' birth month, for face-to-face interviews (Kong, 2010, pp. 137, 146; Akguc et al., 2014). A total of 8,500 respondents were interviewed (Tani, 2015; Meng et al., 2010; Lee \& Zhao, 2015; Zhang, 2017, p. 115). The wave 1 survey took place between March and May 2008, and the wave 2 survey between March and May 2009 (Meng et al., 2010). Migrants were defined as individuals who had left their rural households and resided in urban regions for six months or longer (Meng et al., 2010; Connelly \& Maurer-Fazio, 2015; Kong, 2010, p. 136; Demurger \& Wang, p. 2016).

The 2008 financial crisis had a severe impact on industries where rural migrant workers were concentrated, including manufacturing, construction and services industries (Kong, 2010, p. 149). As a result, as indicated by Table 3, the attrition rate of wave 2 of the MHS was as high as $58.4 \%$ (Akguc et al., 2014). Due to sample attrition, an equivalent number of new households were supplemented in wave 2 based on exactly the same sampling procedures as those used in wave 1 (Zhao, 2015, pp. 88-9; Kong, 2010, p. 149).

While survey teams gathered new respondents to participate in the wave 2 survey as a compensation, these replacements were unlikely to share an identical socioeconomic status, common mental health conditions and demographic characteristics as those lost (Meng et al., 2010). Therefore, this project only analysed data from respondents who took part in both wave 1 and wave 2 of the survey. In doing so, potential non-response bias, ascribed to the high attrition rate, was reduced. This also facilitated direct comparison between the wave 1 and wave 2 datasets, for the purposes of studying how psychosocial wellbeing of rural migrant workers was affected as an outcome of the 2008 financial crisis.

\subsection{GHQ-12}

The MHS datasets include the General Health Questionnaire (GHQ-12), developed by David Goldberg (1972), a self-administered screening questionnaire compiled to assess respondents with minor, common mental disorders (Friedman, 2013; Goldberg et al., 1997; Sanchez-Lopez \& Dresch, 2008, p. 839). The GHQ-12 comprises 12 items, each examining an aspect of mental or psychosocial wellbeing on a four-point (less than usual, no more than usual, rather more than usual, or much more than usual) scale (Tani, 2015; Goldberg \& Williams, 1998; Montazeri et al., 2003, p. 66; Zulkefly \& Baharudin, 2010, p. 74). Assessed pathologies include depressive symptoms, anxious symptoms, distress, a sense of loneliness and isolation (Zhong et al., 2015, p. 2; Shen et al., 1998, pp. 5370, 5372; Liu et al., 2009; Li et al., 2008). This project employed the bi-modal (0-0-1-1) scoring method, resulting in a score for each item of either 0 or 1 , in addition to a total score between 0 (best status of wellbeing) and 12 (worst status of wellbeing) (Crockett et al., 2009, p. 335; Hankins, 2008, p. 355; Akay et al., 2012a, p. 424; Akay et al., 2012b, p. 5). This project corresponded with existing Chinese literature, adopting the 
cut-off point of 3/4 for common mental disorders (CMDs) diagnosis (Liang et al., 2016; Politi et al., 1994; Ip \& Martin, 2006, p. 91).

GHQ-12 scores, categorised as the presence of CMDs vs. the absence of CMDs, were chosen as the dependent variable. Socioeconomic status was measured as per hukou status, job nature and working hours, each treated as an independent variable. City, gender, age, ethnicity and educational level were taken into account as confounders.

The formula of inferential binary logistic regression model was written, as follows:

$$
\begin{gathered}
\mathrm{Y}_{\mathrm{CMDs}}=\alpha+\beta_{\text {gender }} \mathrm{X}_{\text {gender i }}+\beta_{\text {age }} \mathrm{X}_{\text {age i }}+\beta_{\text {ethnicity }} \mathrm{X}_{\text {ethnicity i }}+\beta_{\text {hukou }} \mathrm{X}_{\text {hukou i }}+\beta_{\text {education }} \mathrm{X}_{\text {education i }}+ \\
\beta_{\text {job }} \mathrm{X}_{\text {job i }}+\beta_{\text {workinghours }} \mathrm{X}_{\text {workinghours i }}
\end{gathered}
$$

where $\mathrm{Y}_{\mathrm{CMDs}}=\log \left(\mathrm{Odds}_{\mathrm{i}}\right)$;

$\operatorname{Odds}_{\mathrm{i}}=\log \left[\pi_{\mathrm{i}} /\left(1-\pi_{\mathrm{i}}\right)\right]$;

$$
\pi_{\mathrm{i}}=\exp \left(\alpha+\beta_{\text {gender }} \mathrm{X}_{\text {gender i }}+\beta_{\text {age }} \mathrm{X}_{\text {age i ... }}+\beta_{\text {workinghours }} \mathrm{X}_{\text {workinghours } \mathrm{i}}\right) /\left[1+\exp \left(\alpha+\beta_{\text {gender }} \mathrm{X}_{\text {gender i }}+\beta_{\text {age }} \mathrm{X}_{\text {age i .... }}+\right.\right.
$$

\section{Statistical Method}

The software package STATA 14.2 was used for secondary data analysis.

\section{Data Analysis}

The legal retirement age in China was 60, although rural migrant workers running small businesses were not bound to the statutory retirement age due to the absence of an employment contract (James 2007 p. 60). It is noteworthy that rural migrant worker samples might under-report their ages, as a result of their socioeconomic needs to continue working rather than retiring. Also, according to the People's Republic of China (PRC) Labour Law, the minimum age for working was 16 (Library of Congress 2015). This project therefore restrictively analysed sample data between the age of 16 and 64 .

Cross-tabulations were employed in order to crudely assess the relationships between each categorical confounder or explanatory variable, and the response variable. Here response variable was categorised as better mental health or worse mental health, a categorisation based on the cut-off point 3/4 of GHQ-12 scores. Then, Chi-square tests were performed to examine whether population means of two samples were equal, or substantially different. One Chi-square test, for example, aimed to analyse the differences in mental health conditions between male and female rural migrant worker samples. Next, logistic regression was performed for wave 1 and 2 data separately, for the purpose of measuring the impact on mental health imposed by several health predictors, after controlling specific characteristics of rural migrant worker samples. Here significance level was set at 0.05 .

\section{Results}

\subsection{Cross-tabulations}

\subsubsection{Education Level and Mental Health}

In line with existing literature, rural migrant worker samples enjoyed different levels of mental health by education level between 2008 and 2009 (Chi-square test: $\mathrm{p}<0.001 ; \mathrm{N}=2,364$ ). Education level was measured by the highest educational qualification samples received. The poorest educated samples, those who completed elementary school or below, were most likely to develop CMDs (12.09\% diagnosis rate in 2008 and $17.27 \%$ diagnosis rate in 2009). In 2008, rural migrant worker samples who had received secondary and post-secondary, but not tertiary education, were least likely to suffer from CMDs (between 3.33\% and 5.74\% diagnosis rates). In 2009 , while all non-tertiarily educated rural migrant worker samples encountered more mental health struggles (between $6.47 \%$ and $17.27 \%$ diagnosis rates of CMDs), samples with tertiary education levels were not diagnosed with CMDs (Table 4). While the mental health of the majority of rural migrant worker samples was seemingly affected by the 2008 financial crisis, the most educated samples were unlikely to experience any adverse impact on their mental wellbeing.

\subsection{Binary Logistic Regression}

\subsubsection{Education Level and Mental Health}

In 2008, when looking at rural migrant worker samples who did not receive tertiary education, keeping confounders and alternative explanatory variables constant, the odds of being CMDs-free for samples reaching junior middle school, senior middle school and post-secondary school level were 1.56, 1.41 and 1.30 times that 
of samples finished elementary school level or below at 0.05 significance level. This suggests that the more educational qualifications rural migrant worker samples received, the more likely they were to be free from CMDs. However, it was not statistically significant to argue tertiarily-educated rural migrant worker samples enjoyed different levels of mental wellbeing than their counterparts who had completed elementary school or below (Table 5).

In 2009, the odds of rural migrant worker samples finishing up to junior middle and senior middle school being free from CMDs were 1.79 and 1.35 respectively that of samples possessing educational qualification of up to elementary school level at 0.05 significance level. This again indicates that the more education rural migrant worker samples had completed, the less likely they were to suffer from CMDs. However, those who obtained post-secondary educational qualifications were no less likely to develop CMDs than those who, at most, had received elementary education (Table 5).

\subsubsection{Occupational Conditions and Mental Health}

Despite existing literature argues that both educational level and occupation play an important role in rural migrant workers' psychosocial and mental wellbeing, there was no evidence to suggest that rural migrant worker samples were more likely to experience CMDs based on their jobs (non-manual vs. manual vs. self-employed vs. family business) or working hours ( $<60$ hours per week vs. 60-119 hours per week vs. $>=120$ hours per week) at 0.05 significance level (Table 5). These findings suggest rural migrant worker samples undertaking non-manual jobs, alongside those working less than 60 hours per week, did not experience fewer psychological challenges.

\section{Discussion}

\subsection{Education Levels, Socioeconomic Expectations and Mental Health}

Education level is a primary predictor of how well rural migrant workers can adapt and remain satisfied with their socioeconomic status. Based on aforementioned studies, better educated samples should expect, and experience, better working conditions, with less discrimination and social exclusion, resulting in better mental health (Zhong et al., 2015, p. 5; Cao \& Liu, 2015, p. 465; Zhu et al., 2012, pp. 497, 501; Frenkel \& Chongxin 2015, pp. 262, 266, 268). However, when there is a significant discrepancy between expected and actual socioeconomic outcomes, better educated rural migrant workers could suffer from poorer mental health (Cheng et al., 2013, pp. 2162, 2164; Nielsen \& Smyth, 2006, p. 5).

The higher the education level of rural migrant workers, the more likely they were to be aware of occupational and social equality rights. This means better educated rural migrant workers had higher expectations of getting a fair share of occupational and social welfare (Chan \& Ngai, 2010). Based on existing literature, rural migrant workers who obtained higher educational qualifications resulted in greater career advancement and decreased chances of facing social marginalisation, leading to better mental health. Meanwhile, rural migrant workers with higher education level expected more for their social and occupational development, resulting in a greater risk of widening the gaps between expected and actual rewards in life and, as a consequence, poorer mental health (Cheng et al., 2013, pp. 2162, 2164; Nielsen \& Smyth, 2006, p. 5).

These arguments corresponded to the findings that indicated why better educated rural migrant worker samples were less likely to suffer from CMDs, yet the most and least educated samples were at greater risk of being diagnosed with CMDs. Findings revealed that the optimal educational level to enhancing mental wellbeing was between senior secondary school and post-secondary school level within rural migrant worker communities.

\subsection{Occupational Security and Mental Health}

In spite of the associations between socioeconomic and mental wellbeing among China's rural migrant workers, findings did not suggest that rural migrant worker samples in non-manual jobs and working fewer hours enjoyed better mental health than those engaging in manual tasks and committing to over 60 hours of work per week (Hu \& Chen, 2012; Jin et al., 2012; Lin et al., 2011; Yang et al., 2012; Hu et al., 2012).

Based on the availability of the datasets, this project considered job nature and weekly working hours when measuring occupational security, despite the fact that there are many alternative predictors of job security, including wage earnings and risks of unemployment (Chan, 2010b, pp. 666-77; Solinger, 2006, p. 184, 191; Frenkel \& Yu, 2015, p. 267). Here longer working hours experienced by rural migrant worker samples might not necessarily worsen their mental health if such a circumstance inferred higher wage earnings and slimmer risks of unemployment, factors which could potentially compensate for the negative mental impacts caused by prolonged working hours (Chan, 2016, p. 6). 
It is noteworthy that rural migrant workers were denied non-wage incomes, including housing subsidies and health care services, due to their rural hukou status. However, additional studies argue that having higher wage earnings was associated with more remittance, allowing rural migrant workers to send the surplus their rural-based families (Yang \& Fang, 2000 p. 9; Cai, 2003; DeWind \& Holdaway, 2008, p. 221). Sending remittance in this case represented stronger family ties, higher degrees of interconnectivity between rural migrant workers and families, better familial standards of living, and greater emotional support for the rural migrant workers (Cai, 2003, pp. 472-3). This project was unable to explore earnings, or even remittance levels, as part of the inferential statistical model, limiting the applicability of findings when measuring occupational security. Without including extensive socioeconomic predictors of mental health in the model, these functional shortcomings might help explain the failure to suggest a positive association between socioeconomic and mental wellbeing among rural migrant worker samples in the findings, an association that existing studies supported.

Another possibility to explain why there was no association between socioeconomic and mental wellbeing between 2008 and 2009 was the introduction of the Labour Contract Law on $1^{\text {st }}$ January 2008. The Labour Contract Law 2008 significantly improved the socioeconomic security enjoyed by rural migrant workers through, for example, requiring all employers to sign labour contracts with employees, protecting long-service employees against dismissal and limiting the use of temporary contracts (Wang et al., 2009, p. 487, 490; Xu, 2013, p. 244). Under the implementation of the Labour Contract Law, China's labour regulations resulted in significant improvement in employment security as relative to those of other countries. According to the measure of Employment Protection Legislation (EPL) strictness, as applied to the Organisation for Economic Co-operation and Development (OECD) countries, China ranked third in EPL strictness among OECD countries after the enforcement of the Law (Gallagher et al., 2013, p. 2). The enhancement in rural migrant workers' occupational security could plausibly raise their job satisfaction to some extent, reducing the possible socioeconomic drivers towards mental illnesses faced by these samples. The argument was supported by Qian Gao et al. (2012, p. 1196) and Haiyan Wang et al. $(2009$, pp. 487, 489) who claimed rural migrant workers with permanent or longterm contracts (1 year and above) were significantly more likely to enjoy social insurance coverage. Here social insurance coverage in urban China referred to pensions, medical, unemployment, work injury and maternity insurance.

\subsection{Rural Migrant Workers' Mental Health in 2009}

After the collapse of Lehman Brothers, between late and to early 2009, consumer demands on "made in China" products were dampened and the number of export orders from China dried up (Haan, 2010, p. 759). This resulted in a substantial surplus of rural migrant workers and created mass urban unemployment. China's National Bureau of Statistics (NBSC) statistics, released in March 2009, revealed that an estimated 23 million rural migrant workers were laid-off between third quarter of 2008 and first quarter of 2009 (Huang et al., 2010 p. 3 ). The majority of this cohort returned to villages and re-engaged in agricultural work (Chan $2010 \mathrm{~b} \mathrm{p.} \mathrm{660;}$ Fang \& Cai, 2009, p. 513). During the first quarter of 2009, an estimated 10 million of those dismissed rural migrant workers returned to villages (Zhang, 2015, p. 69; Chen et al., 2012). Moreover, the mass unemployment caused by the 2008 financial crisis also impacted rural migrant workers who had started their small businesses in cities, in part because these small business owners were not protected by the Labour Contract Law (Fang \& Chan, 2009, p. 516).

Unforeseen financial uncertainty significantly worsened the relative socioeconomic security of all rural migrant workers in 2009. Jikun Huang et al. (2010) argued both employed and laid-off rural migrant workers encountered some extent of barriers to maintain their socioeconomic wellbeing after the mass unemployment, leading to financially difficulties in making ends meet and sending remittance to families. As a consequence, rural migrant worker samples with varying degrees of socioeconomic wellbeing, as measured by job nature and working hours, did not suffer from different levels of mental illness in 2009, relative to those sampled in 2008.

\section{Conclusions}

This research demonstrated the 2008 financial crisis did not worsen the socioeconomic vulnerability faced by rural migrant workers. It is noteworthy that educational attainment is a prominent indicator if rural migrant workers would like to enhance their socioeconomic wellbeing. However, due to the unforeseen financial uncertainty and mass unemployment between 2008 and 2009, better educated rural migrant workers' occupational expectations should be realistic. Otherwise, they could be disappointed with their occupational attainment, leading to possible negative impacts on their psychosocial wellbeing. Since the introduction of 2008 Labour Contract Law might also affect the socioeconomic profile of rural migrant workers, future research should analyse additional waves of the MHS (i.e. wave 3, wave 4 and wave 5) to better understand both the 
socioeconomic and psychosocial wellbeing of such cohorts. Moreover, additional socioeconomic factors should be taken into account in order to fully address job security faced by rural migrant workers in further detail.

\section{References}

Books

Braun, J. (2008). Food and Financial Crises: Implications for Agriculture and the Poor. Washington, DC: International Food Policy Research Institute.

Chan, A. (2016). China's Workers Under Assault: Exploitation and Abuse in a Globalising Economy. London: Routledge.

Davin, D. (1999). Internal Migration in Contemporary China. London: Macmillan Press Ltd.

DeWind, J. and Holdaway, J. (2008). Migration and Development Within and Across Borders: Research and Policy Perspectives on Internal Migration. Brooklyn, NY: The Social Science Research Council.

Gaetano, A. (2015). Out to Work: Migration, Gender, and the Changing Lives of Rural Women in Contemporary China. Honolulu, HI: University of Hawai'i Press.

Gallagher, M. et al. (2009). OECD Review of Tertiary Education: China. Paris: OECD Publishing.

Goldberg, D., \& Williams, P. (1988). A User's Guide to the General Health Questionnaire. London: NFER-Nelson.

Jones, S. et al. (2010). Time for a Visible Hand: Lessons from the 2008 World Financial Crisis. Oxford: Oxford University Press.

Wang, F. (2005). Organizing Through Division and Exclusion: China's Hukou System. Stanford, CA: Stanford University Press.

Young, J. (2013). China's Hukou System: Markets, Migrants and Institutional Change. Wellington: Springer.

Book Chapters

Chan, K. W. (2015). Five Decades of the Chinese Hukou System. In R. Iredale, \& F. Guo (Eds.), Handbook of Chinese Migration: Identity and Wellbeing (pp. 23-47). Cheltenham: Edward Elgar Publishing.

Chan, C. et al. (2010). The Role of the State, Labour Policy and Migrant Workers' Struggles in Globalized China. In P. Bowles, \& J. Harriss (Eds.), Globalization and Labour in China and India: Impacts and Responses (pp. 45-63). London: Palgrave Macmillan.

Chan, K. W. (forthcoming). China, Internal Migration. In I. Ness (Ed.), The Encyclopedia of Global Migration. New York, NY: Blackwell Publishing.

Fan, C. (2008). Migration, Hukou and the City. In S. Yusuf, \& T. Saich (Eds.), China Urbanizes: Consequences, Strategies and Policies (pp. 65-89). Directions in Development Countries and Regions. Washington, DC: The World Bank.

Garnaut, R. et al. (2008). China's Rapid Emissions Growth and Global Climate Change Policy. In L. Song, \& W. T. Woo (Eds.), China's Dilemma: Economic Growth, the Environment and Climate Change (pp. 170-189). Canberra: Australian National University Press.

Kong, S. (2010). Rural-Urban Migration in China: Survey Design and Implementation. In X. Meng, \& C. Manning (Eds.), The Great Migration: Rural-Urban Migration in China and Indonesia (pp. 135-152) Cheltenham: Edward Elgar Publishing Ltd.

Journal Articles

Akay, A. et al. (2012a). Relative Concerns of Rural-to-Urban Migrants in China. Journal of Economic Behavior \& Organization, 81(2), 421-441. https://doi.org/10.1016/j.jebo.2011.12.006

Akgüç, M. et al. (2014). The RUMiC Longitudinal Survey: Fostering Research on Labor Markets in China. IZA Journal of Labor and Development, 3(1). https://doi.org/10.1186/2193-9020-3-5

Bankston, C., \& Zhou, M. (1997). The Social Adjustment of Vietnamese American Adolescents: Evidence for a Segmented-Assimilation Approach. Social Science Quarterly, 8(2), 508-523.

Bourkhis, K., \& Nabi, M. S. (2013). Islamic and Conventional Banks' Soundness During the 2007-2008 Financial Crisis. Review of Financial Economics, 22(1), 68-77. https://doi.org/10.1016/j.rfe.2013.01.001

Cai, F., \& Chan, K. W. (2009). The Global Economic Crisis and Unemployment in China. Eurasian Geography 
and Economics, 50(5), 513-531. https://doi.org/10.2747/1539-7216.50.5.513

Cai, Q. (2003). Migrant Remittances and Family Ties: A Case Study in China. International Journal of Population Geography, 9(6), 471-483. https://doi.org/10.1002/ijpg.305

Cao, Y., \& Liu, Z. (2015). Poverty and Health: Children of Rural-to-Urban Migrant Workers in Beijing, China. Social Indicators Research, 123(2), 459-477. https://doi.org/10.1007/s11205-014-0748-x

Chan, J., \& Pun, N. (2010). Suicide as Protest for the New Generation of Chinese Migrant Workers: Foxconn, Global Capital, and the State. The Asia-Pacific Journal, 8(37).

Chan, K. W. (2010a). A China Paradox: Migrant Labor Shortage amidst Rural Labor Supply Abundance. Eurasian Geography and Economics, 51(4), 513-30. https://doi.org/10.2747/1539-7216.51.4.513

Chan, K. W. (2010b). The Global Financial Crisis and Migrant Workers in China: There is No Future as a Labourer; Returning to the Village Has no Meaning. International Journal of Urban and Regional Research; 34(3), 659-677. https://doi.org/10.1111/j.1468-2427.2010.00987.x

Chan, K. W., \& Zhang, L. (1999). The Hukou System and Rural-Urban Migration in China: Processes and Changes. The China Quarterly, 160(1-2), 818-855. https://doi.org/10.1017/S0305741000001351

Chen, L. et al. (2012). Mental Health, Duration of Unemployment, and Coping Strategy: A Cross-Sectional Study of Unemployed Migrant Workers in Eastern China During the Economic Crisis. BMC Public Health, 12(597). http:doi.org/10.1186/1471-2458-12-597. https://doi.org/10.1186/1471-2458-12-597

Cheung, N. (2013). Rural-to-Urban Migrant Adolescents in Guangzhou, China: Psychological Health, Victimization, and Local and Translocal Ties. Social Science \& Medicine, 93(C), 121-129. https://doi.org/10.1016/j.socscimed.2013.06.021

Cheung, N. (2014). Social Stress, Locality of Social Ties and Mental Well-Being: The Case of Rural Migrant Adolescents in Urban China. Health \& Place, 27(1), 142-154. https://doi.org/10.1016/j.healthplace.2014.01.013

Cheng, Z. et al. (2013). Happiness and Job Satisfaction in Urban China: A Comparative Study of Two Generations of Migrants and Urban Locals. Urban Studies, 51(10), 2160-84. https://doi.org/10.1177/0042098013506042

Crockett, R. et al. (2009). Time Orientation and Health-Related Behaviour: Measurement in General Population Samples. Psychology \& Health, 24(3), 333-350. https://doi.org/10.1080/08870440701813030

Editorial. (2014). Migrant's Health in China. The Lancet, 384(9958), 1902. https://doi.org/10.1016/S0140-6736(14)62262-5

Fang, Z. (2017). Panel Quantile Regressions and the Subjective Well-Being in Urban China: Evidence from RUMiC Data. Social Indicators Research, 132(1), 11-24. https://doi.org/10.1007/s11205-015-1126-z

Fong, E., \& Tong, Y. (2015). Can Family Financial Resources Buy Friends? Family Financial Resources and Friendship Patterns Among Migrant Workers in China. American Behavioural Scientist, 59(9), 1083-1099. https://doi.org/10.1177/0002764215580615

Frenkel, S., \& Yu, C. (2015). Chinese Migrants' Work Experience and City Identification: Challenging the Underclass Thesis. Human Relations, 68(2), 261-285. https://doi.org/10.1177/0018726713508991

Fu, Q., \& Ren, Q. (2010). Educational Inequality Under China's Rural-Urban Divide: the Hukou System and Return to Education. Environment and Planning, 42(3), 592-610. https://doi.org/10.1068/a42101

Goldberg, D. et al. (1997). The Validity of Two Versions of the GHQ in the WHO Study of Mental Illness in General Health Care. Psychological Medicine, 27(1), 191-197. https://doi.org/10.1017/S0033291796004242

Gong, P. et al. (2012). Urbanisation and Health in China. The Lancet, 379(9818), 843-52. https://doi.org/10.1016/S0140-6736(11)61878-3

Haan, A. D. (2010). A Defining Moment? China's Social Policy Response to the Financial Crisis. Journal of International Development, 22(6), 758-771. https://doi.org/10.1002/jid.1726

Hankins, M. (2018). The Reliability of the Twelve-Item General Health Questionnaire (GHQ-12) Under Realistic Assumptions. BMC Public Health, 8, 355. http:doi.org/10.1186/1471-2458-8-355.

Hu, R., \& Chen, S. (2012). Social Factors Influencing Peasant Workers' Mental Health (in Chinese). Chinese Sociology and Anthropology, 32(6), 135-157. 
Ip, W., \& Martin, C. (2006). Factor Structure of the Chinese Version of the 12-Item General Health Questionnaire (GHQ-12) in Pregnancy. Journal of Reproductive and Infant Psychology, 24(2), 87-98. https://doi.org/10.1080/02646830600643882

James, E. (2007). How Can China Solve Its Old-Age Security Problem? The Interaction Between Pension, State Enterprise and Financial Market Reform. Journal of Pension Economics \& Finance, 1(1), 53-75. https://doi.org/10.1017/S1474747202001026

Jia, W. (2014). How Much Did the Return of Rural Migrant Labor Affect China's National Economy? China Agricultural Economic Review, 6(1), 38-54. https://doi.org/10.1108/CAER-01-2013-0013

Jin, L. et al. (2012). Trans-Local Ties, Local Ties and Psychological Well-Being Among Rural-to-Urban Migrants in Shanghai. Social Science \& Medicine, 75(2), 288-296. https://doi.org/10.1016/j.socscimed.2012.03.014

Kulis, S. et al. (2009). Perceived Ethnic Discrimination Versus Acculturation Stress: Influences on Substance Use among Latino Youth in the Southwest. Journal of Health and Social Behavior, 50(4), 443-59. https://doi.org/10.1177/002214650905000405

Lau, J. et al. (2012). Suicide in a Mega-Size Factory in China: Poor Mental Health Among Young Migrant Workers in China. Occupational and Environmental Medicine, 69(7), 526. http://doi.org/10.1136/oemed-2011-100593.

Li, H. et al. (2008). Research on the Psychological Health State, Life Events and Coping Style of the Non-Native Enterprises Workers. Chinese Journal of Behavioural Medical Science, 17(9), 819-820.

Li, L. et al. (2007). The Mental Health Status of Chinese Rural-Urban Migrant Workers: Comparison with Permanent Urban and Rural Dwellers. Social Psychiatry and Psychiatric Epidemiology, 42(9), 716-722. https://doi.org/10.1007/s00127-007-0221-0

Liang, Y. et al. (2016). The Factor Structure of the 12-Item General Health Questionnaire (GHQ-12) in Young Chinese Civil Servants. Health and Quality of Life Outcomes, 14(136). http:doi.org/10.1186/s12955-016-0539-y.

Lin, D. et al. (2011). Discrimination, Perceived Social Inequity, and Mental Health Among Rural-to-Urban Migrants in China. Community Mental Health, 47(2), 171-180. https://doi.org/10.1007/s10597-009-9278-4

Liu, F. (2011). Old-Age Insurance for Rural-Urban Migrant Workers in China. Journal of Asian Public Policy, 4(1), 61-75. https://doi.org/10.1080/17516234.2011.574961

Liu, J. et al. (2011). Mental Health System in China: History, Recent Service Reform and Future Challenges. World Psychiatry, 10(3), 210-216. https://doi.org/10.1002/j.2051-5545.2011.tb00059.x

Liu, Y. et al. (2009). The Mental Health Status Among Migrant Workers on the Labor Market in Liaoning. Chinese Journal of Health Education, 25(12), 894-896. https://doi.org/10.1080/13674670802105252

Martikainen, P. et al. (2002). Psychosocial Determinants of Health in Social Epidemiology, Internal Journal of Epidemiology, 31(6), 1091-1093. https://doi.org/10.1093/ije/31.6.1091

Montazeri, A. et al. (2003). The 12-Item General Health Questionnaire (GHQ-12): Translation and Validation Study of the Iranian Version. Health and Quality Life Outcomes, 1, 66. http:doi.org/10.1186/1477-7525-1-66.

Noh, S., \& Avison, W. (1996). Asian Immigrants and the Stress Process: A Study of Koreans in Canada. Journal of Health and Social Behavior, 37(2), 192-206. https://doi.org/10.2307/2137273

Politi, P. et al. (1994). Reliability, Validity and Factor Structure of the 12-Item General Health Questionnaire Among Young Males in Italy. Acta Psychiatrica Scandinavica, 90(6), 432-437. https://doi.org/10.1111/j.1600-0447.1994.tb01620.x

Reich, G. (2014). The Employment Effects of Credit Market Disruptions: Firm-Level Evidence From the 2008-9 Financial Crisis. Quarterly Journal of Economics, 129(1), 1-59. https://doi.org/10.1093/qje/qjt031

Qian G. et al. (2012). Labour Contracts and Social Insurance Participation Among Migrant Workers in China. China Economic Review, 23(4), 1196-1205. https://doi.org/10.1016/j.chieco.2012.09.002

Sanchez-Lopez, M., \& Dresch, V. (2008). The 12-Item General Health Questionnaire (GHQ-12): Reliability, External Validity and Factor Structure in the Spanish Population. Psicothema, 20(4), 839-843.

Shen, Q. et al. (1998). A Preliminary Study of the Mental Health of Young Migrant Workers in Shenzhen. 
$\begin{array}{llll}\text { Psychiatry } \quad \text { and } \quad \text { Clinical } & \text { Neurosciences, } & \text { 52(Supp.), }\end{array}$ https://doi.org/10.1111/j.1440-1819.1998.tb03272.x

Solinger, D. (2006). The Creation of a New Underclass in China and its Implications. Environment \& Urbanization, 18(1), 177-193. https://doi.org/10.1177/0956247806063972

Song, Y., \& Sun, W. (2016). Health Consequences of Rural-to-Urban Migration: Evidence from Panel Data in China. Health Economics, 25(10), 1252-1267. https://doi.org/10.1002/hec.3212

Tani, M. (2017). Hukou Changes and Subjective Well-Being in China. Social Indicators Research, 132(1), 47-61. https://doi.org/10.1007/s11205-016-1247-z

Wang, H. et al. (2009). China's New Labour Contract Law: is China moving towards increased power for workers. Third World Quarterly, 30(3), 485-501. https://doi.org/10.1080/01436590902742271

Wang, J. et al. (2017). Prevalence of Mental Health Problems and Associated Risk Factors among Rural-to-Urban Migrant Children in Guangzhou, China. International Journal of Environmental Research and Public Health, 14(11), 1385-1399. https://doi.org/10.3390/ijerph14111385

Wang, M. (2010). Impact of the Global Economic Crisis on China's Migrant Workers: A Survey of 2,700 in 2009. Eurasian Geography and Economics, 51(2), 218-235. https://doi.org/10.2747/1539-7216.51.2.218

$\mathrm{Xu}$, Y. (2013). Labour Non-Governmental Organisations in China: Mobilising Rural Migrant Workers. Journal of Industrial Relations, 55(2), 243-259. https://doi.org/10.1177/0022185612473222

Yang, T. et al. (2012). Mental Health Status and Related Characteristics of Chinese Male Rural-Urban Migrant Workers. Community Mental Health Journal, 48(3), 342-351. https://doi.org/10.1007/s10597-011-9395-8

Young, M. (2001). Moderators of Stress in Salvadoran Refugees: The Role of Social and Personal Resources. International Migration Review, 35(3), 840-869. https://doi.org/10.1111/j.1747-7379.2001.tb00043.x

Yu, B. et al. (2017). Migration Stress, Poor Mental Health, and Engagement in Sex with High-Risk Partners: a Mediation Modeling Analysis of Data from Rural-to-Urban Migrants in China. Sexuality Research and Social Policy, 14(4), 467-477. https://doi.org/10.1007/s13178-016-0252-y

Zhao, G. (2015). Can Money 'Buy' Schooling Achievement? Evidence from 19 Chinese Cities. China Economic Review, 35(1), 83-104. https://doi.org/10.1016/j.chieco.2015.06.004

Zhang, H. (2017). Opportunity or New Poverty Trap: Rural-Urban Education Disparity and Internal Migration in China. China Economic Review, 44(1), 112-124. https://doi.org/10.1016/j.chieco.2017.03.011

Zhang, Y. (2015). Social Impacts of the Global Financial Crisis on China and its Policy Initiatives. China Journal of Social Work, 8(1), 65-77. https://doi.org/10.1080/17525098.2015.1009136

Zhi, H. et al. (2013). Impact of the Global Financial Crisis in Rural China: Gender, Off-Farm, Employment, and Wages. Feminist Economics, 19(3), 238-266. https://doi.org/10.1080/13545701.2013.809137

Zhong, B. et al. (2015). Prevalence and Correlates of Major Depressive Disorder Among Rural-to-Urban Migrant Workers in Shenzhen, China. Journal of Affective Disorders, 183(1), 1-9. https://doi.org/10.1016/j.jad.2015.04.031

Zhu, C. et al. (2012). Correlates of Quality of Life in China Rural-Urban Female Migrant Workers. Quality of Life Research, 21(3), 495-503. https://doi.org/10.1007/s11136-011-9950-3

Zulkefly, N., \& Baharudin, R. (2010). Using the 12-Item General Health Questionnaire (GHQ-12) to Assess the Psychological Health of Malaysian College Students. Global Journal of Health Science, 2(1), 73-80. https://doi.org/10.5539/gjhs.v2n1p73

Working Papers

Akay, A. et al. (2012b). Remittances and Well-Being Among Rural-to-Urban Migrants in China. Discussion Paper series, Forschungsinstitut zur Zukunft der Arbeit, No. 6631. Institute for the Study of Labor (IZA).

Aisen A., \& Franken, M. (2010). Bank Credit During the 2008 Financial Crisis: A Cross-Country Comparison. Working Paper No. 10/47. Washington, D.C.: International Monetary Fund.

Brooks, N. (2003). Vulnerability, Risk and Adaption: A Conceptual Framework. Tyndall Centre Working Paper 38. Norwich: Tyndall Centre for Climate Change Research.

Connelly, R., \& Maurer-Fazio, M. (2015). Left Behind, At Risk, and Vulnerable Elders in Rural China: What the RUMIC Data Reveal about the Extent, Causes, and Consequences of Being Left Behind. IZA Discussion 
Papers No. 9213.

Démurger, S., \& Wang, X. (2016). Remittances and Expenditure Patterns of the Left Behinds in Rural China. IZA Discussion Papers No. 9640.

Fang, T. et al. (2015). The Use and Impact of Job Search Procedures by Migrant Workers in China. IZA Discussion Papers No. 9438.

Gawande, K. et al. (2011). Determinants of Trade Policy Responses to the 2008 Financial Crisis. Policy Research Working Paper 5862. Washington, D.C.: The World Bank.

Huang, J. et al. (2010). The Impact of the Global Financial Crisis on Off-farm Employment and Earnings in Rural China" Policy Research Working Paper 5439. Washington, D.C.: The World Bank Development Research Group.

Lee, W., \& Zhao, Z. (2015). Height, Weight and Well-Being for Rural, Urban and Migrant Workers in China. IZA Discussion Papers No. 9397.

Meng, X. et al. (2010). How Much Do We Know About the Impact of the Economic Downturn on the Employment of Migrants? ADBI Working Paper Series No. 194.

Nielsen, I., \& Smyth, R. (2006). Job Satisfaction and Response to Incentives Among China's Urban Workforce. Working Paper 23/06. Melbourne: Monash University Department of Management.

Tani, M. (2015). Hukou Changes and Subjective Well-Being. IZA Discussion Papers No. 9451.

Wim, N. (2009). The Financial Crisis of 2008 and the Developing Countries. WIDER Discussion Papers No. 2009/01. Helsinki: World Institute for Developing Economics (UNU-WIDER).

Yang, D., \& Fang, C. (2010). The Political Economy of China's Rural-Urban Divide. Working Paper No. 62. Stanford, CA: Center for Research on Economic Development and Policy Reform, Stanford University.

\section{Online Sources}

Friedman, J. (2013). The Relationships Between the Housing Arrangements and Subjective Wellbeing of Rural-to-Urban Migrants in China. Preliminary Draft. Retrieve from http://citeseerx.ist.psu.edu/viewdoc/summary?doi=10.1.1.643.8323.

Library of Congress (2015). Children's Rights: China. Retrieve from https:/www.loc.gov/law/help/child-rights/china.php.

World Health Organisation (2013). Mental Health Action Plan 2013-2020. Retrieved from http://apps.who.int/iris/bitstream/handle/10665/89966/9789241506021_eng.pdf;jsessionid=0B12CC5D1C9 7547132D6C296E0ABA150? sequence $=1$

Others

National Bureau of Statistics (2007). Situation of rural migration in China in 2006. Internal Research Report No. 18.

\section{Appendix}

Table 1. Migrant Household Survey (MHS)-Spatial Coverage

\begin{tabular}{cc}
\hline Spatial Unit & MHS-City \\
\hline & Bengbu \\
& Chengdu \\
& Chongqing \\
& Dongguan \\
Coverage (provinces/cities) & Guangzhou \\
& Hefei \\
& Hangzhou \\
& Luoyang \\
& Nanjing \\
& Ningbo \\
& Shanghai \\
\hline
\end{tabular}


Shenzhen

Wuhan

Wuxi

Zhengzhou

Source: MHS Wave 1 and 2.

Table 2. Questionnaire Modules

\begin{tabular}{|c|c|c|}
\hline & MHS-Wave 1 & MHS-Wave 2 \\
\hline Personal characteristics & $\checkmark$ & $\checkmark$ \\
\hline Social insurance & $\checkmark$ & $\checkmark$ \\
\hline Health status & $\checkmark$ & $\checkmark$ \\
\hline Supplementary health condition questions & $\checkmark$ & $\checkmark$ \\
\hline Subject wellbeing & $\checkmark$ & $\checkmark$ \\
\hline Risk and preferences & $\checkmark$ & $\checkmark$ \\
\hline Education and training background & $\checkmark$ & $\checkmark$ \\
\hline Employment situation & $\checkmark$ & $\checkmark$ \\
\hline Information on young children $(<=16$ years old $)$ & $\checkmark$ & $\checkmark$ \\
\hline Information on adult children ( $>16$ years old) & $\checkmark$ & \\
\hline Information on spouse living apart & $\checkmark$ & $\checkmark$ \\
\hline Information on parents & $\checkmark$ & $\checkmark$ \\
\hline Information on siblings & $\checkmark$ & $\checkmark$ \\
\hline Social network & $\checkmark$ & $\checkmark$ \\
\hline Information on farmland & $\checkmark$ & $\checkmark$ \\
\hline Life events & $\checkmark$ & $\checkmark$ \\
\hline Comparison of satisfaction level and income & $\checkmark$ & $\checkmark$ \\
\hline Household income, expenditure, assets & $\checkmark$ & $\checkmark$ \\
\hline Durable good listing & $\checkmark$ & $\checkmark$ \\
\hline Present housing and living conditions & $\checkmark$ & $\checkmark$ \\
\hline Information on rural hometown & $\checkmark$ & $\checkmark$ \\
\hline
\end{tabular}

MHS refers to Migrant Household Survey.

Wave 1 data were collected between March and May 2008.

Wave 2 data were collected between March and May 2009.

Table 3. Attrition Rates

\begin{tabular}{lll}
\hline Wave 1 & 5,007 & 8,446 \\
Wave 2 & 5,243 & 9,347 \\
Tracked & 1,821 & 3,512 \\
(Attribution rate) & $63.6 \%$ & $58.4 \%$ \\
Add members & & 409 \\
New samples & 3,422 & 5,426 \\
\hline
\end{tabular}

Source: MHS Wave 1 and 2. 
Table 4. Cross Tabulations, Migrant Household Survey (MHS)

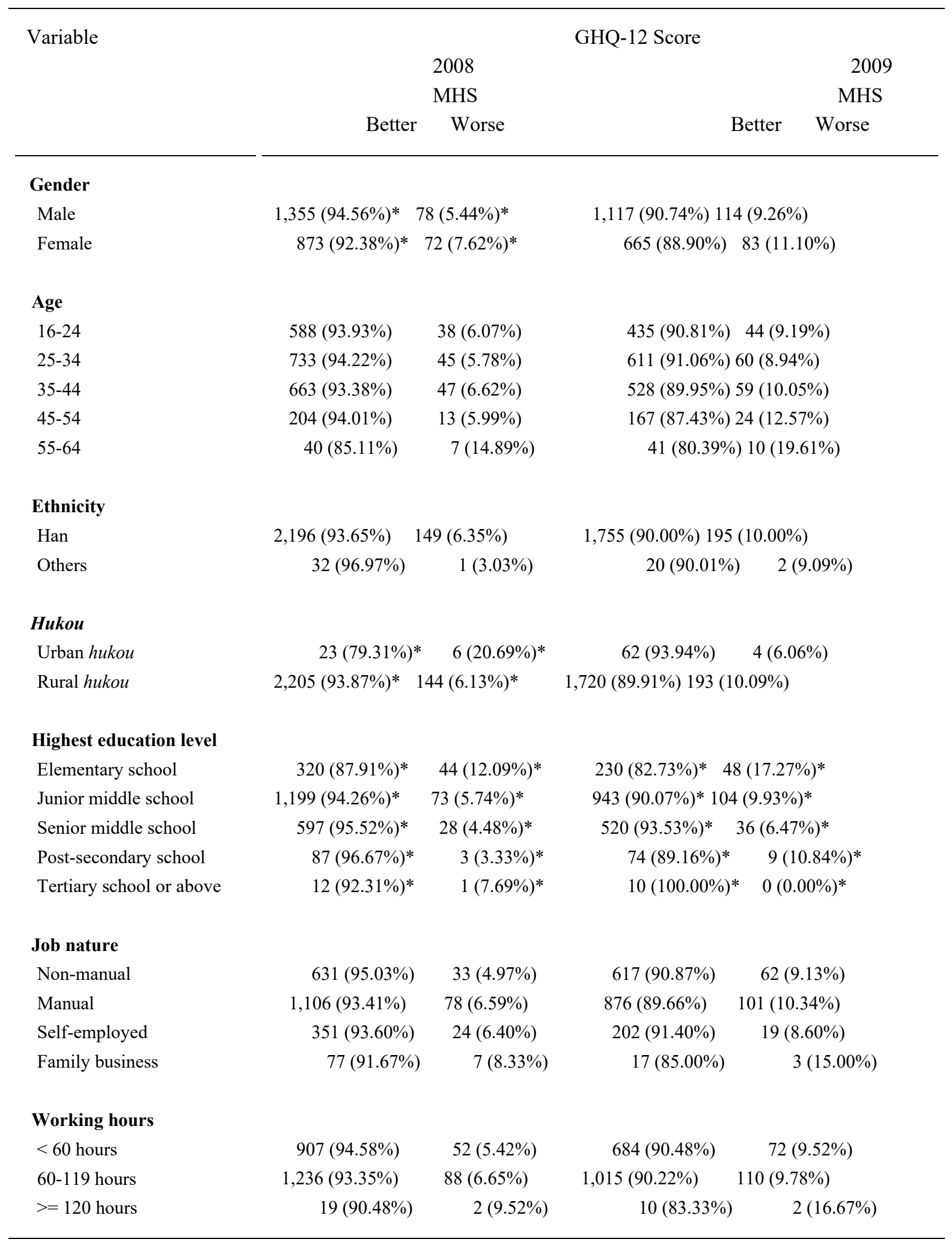

* GHQ-12 = General Household Questionnaire-12.

The cut-off point for good and bad mental health is $3 / 4$.

* represents the chi-square value of the cross-tabulation is 0.05 or above, otherwise under 0.05 . 
Table 5. Logistic Regression Models, Migrant Household Survey (MHS)

\begin{tabular}{|c|c|c|c|c|c|c|c|c|c|}
\hline \multirow{3}{*}{$\begin{array}{l}\text { GHQ - } 12 \\
\text { Gender }\end{array}$} & \multicolumn{5}{|c|}{2008} & \multicolumn{4}{|c|}{2009} \\
\hline & \multirow{4}{*}{$\begin{array}{l}\text { Odds Ratio } \\
\\
\text { Reference } \\
1.30\end{array}$} & \multicolumn{4}{|c|}{ 95\% Conf. Interval P-value } & \multicolumn{4}{|c|}{ Odds Ratio 95\% Conf. Interval P-value } \\
\hline & & & & & & & & & \\
\hline Male & & l & & & / & Reference & & / & / \\
\hline Female & & 0.91 & 1.87 & 0.1 & & 1.26 & 0.91 & 11.75 & 0.163 \\
\hline \multicolumn{10}{|l|}{ Age } \\
\hline $16-24$ & Reference & & l & / & & Reference & & / & l \\
\hline $25-34$ & 0.85 & 0.53 & 1.36 & 0. & 496 & 1.14 & 0.57 & $7 \quad 1.35$ & 0.557 \\
\hline $35-44$ & 0.78 & 0.47 & 1.28 & 0.3 & 327 & 1.22 & 0.52 & $2 \quad 1.30$ & 0.402 \\
\hline $45-54$ & 0.77 & 0.39 & 1.53 & 0.4 & 51 & 0.37 & 0.68 & $8 \quad 2.10$ & 0.538 \\
\hline $55-64$ & 1.18 & 0.43 & 3.21 & 0.75 & & 0.61 & 0.71 & 13.79 & 0.250 \\
\hline \multicolumn{10}{|l|}{ Ethnicity } \\
\hline Han & Reference & & / & / & & Reference & / & & / \\
\hline Others & 0.41 & 0.05 & 3.11 & 0.3 & 87 & 0.52 & 0.07 & 3.98 & 0.529 \\
\hline \multicolumn{10}{|l|}{ Hukou } \\
\hline Urban hukou & Reference & & / & / & & Reference & / & & / \\
\hline Rural hukou & 0.22 & 0.08 & 0.62 & 0.0 & & 1.59 & 0.57 & 4.48 & 0.378 \\
\hline \multicolumn{10}{|l|}{ Highest education level } \\
\hline Elementary school & Reference & & 1 & / & & Reference & l & & / \\
\hline Junior middle school & 0.45 & 0.29 & 0.70 & 0.00 & & 0.58 & 0.39 & 0.87 & 0.008 \\
\hline Senior middle school & 0.35 & 0.20 & 0.61 & 0.00 & & 0.30 & 0.17 & 0.50 & 0.000 \\
\hline Post-secondary school & 0.26 & 0.07 & 0.93 & 0.03 & & 0.65 & 0.27 & 1.53 & 0.320 \\
\hline Tertiary school or above & 0.53 & 0.06 & 4.73 & 0.56 & & l & / & & l \\
\hline \multicolumn{10}{|l|}{ Job nature } \\
\hline Non-manual & Reference & & 1 & l & & Reference & & l & / \\
\hline Manual & 0.70 & 0.92 & 2.21 & 0.1 & & 1.20 & 0.84 & 1.71 & 0.307 \\
\hline Self-employed & 0.83 & 0.69 & 2.12 & 0.5 & & 0.86 & 0.49 & 1.52 & 0.609 \\
\hline Family business & 0.71 & 0.59 & 3.35 & 0.44 & & 1.63 & 0.45 & 5.86 & 0.452 \\
\hline \multicolumn{10}{|l|}{ Working hours } \\
\hline$<60$ hours & Reference & / & / & / & & Reference & & l & / \\
\hline 60-119 hours & 1.14 & 0.7 & 78 & 1.66 & 0.494 & 0.92 & 0.66 & 1.28 & 0.609 \\
\hline$>=120$ hours & 1.72 & 0.3 & & 7.97 & 0.490 & 1.64 & 0.33 & 8.11 & 0.545 \\
\hline
\end{tabular}

* GHQ-12 = General Household Questionnaire-12.

* GHQ-12 cut-off point is $3 / 4$.

\section{Copyrights}

Copyright for this article is retained by the author(s), with first publication rights granted to the journal.

This is an open-access article distributed under the terms and conditions of the Creative Commons Attribution license (http://creativecommons.org/licenses/by/4.0/). 